BBA 45232

\title{
THE EFFECT OF METABOLIC INHIBITORS ON TRANSPORT AND EXCHANGE OF AMINO ACIDS IN EHRLICH ASCITES CELLS
}

\author{
JOHN A. JACQUEZ AND JAMES H. SHERMAN \\ Departments of Physiology and Biostatistics, and Department of Physiology, \\ The University of Michigan, Ann Arbor, Mich. (U.S.A.)
}

(Received February 23rd, I965)

SUMMARY

I. Cyanide and 2-deoxyglucose inhibit transport fluxes but do not inhibit exchange fluxes of amino acids in Ehrlich ascites cells. This is true whether the exchange flux is of the same order of magnitude as the transport flux or whether it is much greater.

2. These findings are compatible with the assumption that the linkage between the carrier system and energy metabolism is such as to either (i) increase the rate of outward movement of free carrier across the cell membrane, or (ii) increase the rate of dissociation of carrier-amino acid complex at the inner surface of the cell membrane. These findings are not compatible with the assumptions that the linkage is such as (iii) to increase the rate of movement of carrier-amino acid complex across the cell membrane, or (iv) to increase the rate of formation of the carrier-amino acid complex at the outer surface of the cell membrane.

\section{INTRODUCTION}

UsSING $^{1}$ used the term exchange diffusion to describe a process in which an ion exchanges across a membrane separating two phases by a mechanism which involves the formation of a complex with a constituent of the membrane which he called a carrier. He defined this as a one-for-one exchange of the same ion and therefore considered it to be independent of any energy requirement. A similar phenomenon occurs for some sugars and for some amino acids but with these a hetero-exchange, that is, an exchange of one kind of sugar for another or of one kind of amino acid for another has been demonstrated ${ }^{2-5}$. Indeed, a gradient in one amino acid or sugar can be used to induce an uphill flow of another amino acid or sugar; in this case the phenomenon has been called counterflow ${ }^{5,6}$.

If, as with passive transport systems, there is no immediate linkage to cellular metabolism, one would expect a priori that inhibitors of cellular metabolism would have no direct effect on transport or exchange fluxes and that any effects would be non-specific and due to general damage to the cell and particularly the cell membrane. The same cannot be said for active transport systems. Whether or not inhibition of

Abbreviation: KRP-solution, Krebs-Ringer-phosphate solution. 
cellular metabolism can affect exchange fluxes would depend on the nature of the linkage between the carrier system and cellular metabolism. For example, if cellular metabolism were required for the transfer of the carrier-substrate complex across the cell membrane one would expect metabolic inhibitors to inhibit exchange fluxes as well as transport fluxes. On the other hand if cellular metabolism were required only for moving carrier which is not bound to substrate across the membrane, metabolic inhibitors should inhibit transport but not exchange fluxes. Thus the relative effect of metabolic inhibitors on transport and exchange fluxes may give us some information about the nature of the linkage between a carrier system and cellular metabolism. A preliminary exposition of the theoretical effects of inhibitors on some specific models of carrier transport systems has been presented?

One of us has shown in a preliminary study that cyanide and 2,4-dinitrophenol inhibit the transport flux of L-tryptophan in Ehrlich ascites cells but have little or no effect on the flux of L-tryptophan in exchange for intracellular azaserine ${ }^{8}$. The present work was undertaken to study this with a wider range of amino acids and of inhibitors. For this purpose, the exchange of L-methionine inside the cell for L-tryptophan outside the cell was chosen for an initial study of the effects of cyanide, 2,4-dinitrophenol and 2-deoxyglucose. L-Methionine was chosen because in a comparison of a large group of normal amino acids it was found to give the largest exchange flux of L-tryptophan; the methionine exchange flux of L-tryptophan is about 6-fold greater than the active transport flux of $L$-tryptophan ${ }^{9}$. This was followed by a study of the effects of one inhibitor, 2-deoxyglucose, on transport and exchange of a number of different monoamino-monocarboxylic acids.

\section{METHODS AND MATERIALS}

The Ehrlich ascites cells used in these experiments were from a hypotetraploid line carried in this laboratory by weekly intraperitoneal inoculation of o.I $\mathrm{ml}$ of ascites (diluted 4: I with sterile saline) into female Swiss albino mice.

\section{Collection and preparation of ascites cells}

Mice bearing 6-7-day-old ascites were killed by cervical dislocation; the abdomens were opened and the ascites was removed with a pipette. If possible we avoided using ascitic fluids which were very hemorrhagic. A total of $20-50 \mathrm{ml}$ of ascitic fluid was collected into $50 \mathrm{ml}$ of $\mathrm{KRP}$-solution ( $\mathrm{pH} \mathrm{7.0-7.2)} \mathrm{containing} 0.2 \mathrm{mg}$ heparin. The resulting suspension was diluted with an equal volume of distilled water and filtered through a 4 -fold thick layer of cheesecloth. The cells were concentrated by centrifugation, and were washed first with half isotonic KRP-solution then with isotonic KRP-solution and were finally resuspended in KRP-solution to give a suspension with a cytocrit of $0.25^{-0.35}$. These handling procedures do not affect the ability of these cells to concentrate amino acids.

\section{Design of experiments}

In the early experiments, the cell suspension was split into two parts, $A$ and $B$. An equal volume of KRP-solution was added to $\mathrm{A}$, an equal volume of a $40 \mathrm{mM}$ solution of an amino acid (L-methionine in most of the early experiments) in $87 \%$ isotonic KRP-solution was added to $\mathrm{B}$. In later experiments, the cell suspension was 
split into three parts, two of which were incubated with different amino acids. The description of the early experiments will illustrate the design of the experiments. The suspensions were incubated for $30 \mathrm{~min}$ at $37^{\circ}$ with gentle shaking. At the end of this preliminary incubation the suspensions were chilled in an ice bath and centrifuged in the cold. The supernatant fluid was discarded and the cells were washed twice with cold KRP-solution and were finally resuspended to their original volume with cold KRP-solution ( $\mathrm{pH}$ 7.0). If L-methionine was used, the cells of suspension B had an intracellular concentration of $30-40$ mmoles $/ \mathrm{kg}$ water at this stage.

Suspension A was used to measure the transport flux of an amino acid and the effect of an inhibitor on it, $B$ was used to measure the exchange flux of the same amino acid and the effect of an inhibitor on it. For each suspension six Heinicke tubes (twoarmed tubes) were set up according to the standard protocol shown in Table I. The stock solutions of inhibitors were prepared with KRP-solution and were neutralized to a $\mathrm{pH}$ of 7.0-7.I. The final concentrations of inhibitors were $5 \mathrm{mM} \mathrm{NaCN}$, o.oI-I $\mathrm{mM}$

T ABLE I

STANDARD PROTOCOL FOR EXPERIMENTS

\begin{tabular}{|c|c|c|c|c|c|c|}
\hline \multirow[t]{2}{*}{ Tube } & \multicolumn{3}{|c|}{ Arm I of Heinicke tube } & \multicolumn{3}{|c|}{ Arm 2 of Heinicke tube } \\
\hline & $\begin{array}{l}\text { Ascites } \\
\text { suspension } \\
(m l)\end{array}$ & $\begin{array}{l}\text { Inhibitor } \\
(m l)\end{array}$ & $\begin{array}{l}K R P \text {-solution } \\
(m l)\end{array}$ & $\begin{array}{l}\text { KRP-solution } \\
(m l)\end{array}$ & $\begin{array}{l}\text { Inhibitor } \\
(\mathrm{ml})\end{array}$ & $\begin{array}{l}6 m M \\
\text { amino acid } \\
(m l)\end{array}$ \\
\hline
\end{tabular}

\begin{tabular}{|c|c|c|c|c|c|c|}
\hline $\mathbf{I}$ & 2 & - & I & 3 & - & - \\
\hline 2 & 2 & - & I & I & -- & 2 \\
\hline 3 & 2 & - & $\mathbf{I}$ & I & - & 2 \\
\hline 4 & 2 & I & - & 2 & I & - \\
\hline 5 & 2 & $\mathbf{I}$ & - & - & I & 2 \\
\hline 6 & 2 & I & - & - & I & 2 \\
\hline
\end{tabular}

2,4-dinitrophenol or Io $\mathrm{mM}$ 2-deoxyglucose. The final concentration in extracellular fluid of the amino acid whose flux was being measured was always close to $2 \mathrm{mM}$. Tubes I and 4 were used for backgrounds in the analytical methods. It should be noted that each flux was always determined in duplicate. From experience we know that the variation in the measurement of transport fluxes between experiments (i.e. with different preparations of Ehrlich ascites) is $3-4$-fold greater than the variation within experiments. Thus the experiments were designed so that the relevant comparisons could be made within each experiment rather than between experiments. The variation due to technique can then be estimated from the variation between replicates within experiments.

After the Heinecke tubes were set up, they were placed in a water bath at $37^{\circ}$ for preliminary temperature equilibration. For the experiments with cyanide or 2,4-dinitrophenol this was for $2 \mathrm{~min}$, for the experiments with 2-deoxyglucose it was for I min. The Heinecke tubes were all tipped simultaneously to mix the contents of the two arms and the incubations were continued for $2 \mathrm{~min}$. All tubes were then chilled in an ice bath for I min and taken to the cold room for further processing. $2 \mathrm{ml}$ of each suspension were pipetted into $\mathrm{I}_{30} \times \mathrm{I} 5 \mathrm{~mm}$ test tubes and centrifuged at $3500 \mathrm{rev} \cdot \mathrm{sec}$ in a Precision Vari-Hi Speed Centricone centrifuge for $20 \mathrm{~min}$ in the cold. 
The pellet and $\mathrm{r} \mathrm{ml}$ of supernatant fluid were extracted with $75 \%$ ethanol containing $0.05 \%(\mathrm{w} / \mathrm{v})$ and $0.0125 \%(\mathrm{w} / \mathrm{v})$, respectively, of barium acetate and were analyzed. The remainder of each suspension was used to obtain cell counts, packed cell volume and wet and dry weights ${ }^{4}$.

\section{Analytical methods}

In the early experiments with L-tryptophan a spectrophotometric assay was employed ${ }^{10}$. In later experiments labeled amino acids were used. For counting, I ml of our usual $75 \%$ ethanol extract was added to $3 \mathrm{ml}$ absolute ethanol and II $\mathrm{ml}$ of toluene containing $6 \mathrm{~g} / \mathrm{l}$ of 2,5-diphenyloxazole and $0 . \mathrm{I} \mathrm{g} / \mathrm{l}$ of I,4-bis-(5-phenyloxazolyl-2)benzene. The resulting clear solutions were counted in a Nuclear-Chicago liquid scintillation system (Model No. 725) with use of the Channels Ratio technique to determine counting efficiency. For all samples, the measured count rates were 30-Iooo-fold greater than the background count rates and counting efficiencies were in the range 55 to $60 \%$.

\section{Calculations}

The details of the calculations have been described previously ${ }^{4}$. The extracellular space of the pellets was not measured in each experiment. It was estimated from calibration curves relating the sucrose space of pellets prepared by our procedure to pellet volume and pellet water.

\section{Sources of materials}

The unlabeled amino acids which were used were all Grade- $\mathrm{A}$ amino acids from California Biochemicals. The following ${ }^{14} \mathrm{C}$-labeled amino acids were used:

L- $\left[3^{-14} C\right]$ Tryptophan from New England Nuclear, Lot $\mathbf{I} 73-60$, specific activity $23.6 \mathrm{mC} / \mathrm{mmole}$; this was reported to give a single peak on paper chromatograms developed with $n$-butanol-acetic acid-water $(4: 1: 5, v / v)$.

L- $\left[U{ }^{14} C\right]$ Phenylalanine from Nuclear-Chicago, specific activity $282 \mathrm{mC} / \mathrm{mmole}$; purity reported as $98 \%$ on analysis by dilution with L-phenylalanine and was $99 \%$ on analysis by paper chromatography and electrophoresis.

$\mathrm{L}-\left[I^{-14} \mathrm{C}\right]$ Alanine from California Biochemicals, Lot 880298 , specific activity $7.5 \mathrm{mC} / \mathrm{mmole}$; this was reported to give a single symmetric peak on paper chromatograms developed with pyridine-acetic acid-water $(50: 35: 15, \mathrm{v} / \mathrm{v})$ and with $n$-butanol-acetic acid-water $(4: I: 2, v / v)$.

$\left[2^{-14} \mathrm{C}\right]$ Glycine from California Biochemicals, Lot 880288 , specific activity $15.5 \mathrm{mC} / \mathrm{mmole}$; this also was reported to give a single symmetric peak on paper chromatograms developed with pyridine-acetic acid-water $(50: 35: 15, \mathrm{v} / \mathrm{v})$ and with $n$-butanol-acetic acid-water $(4: \mathrm{I}: 2, \mathrm{v} / \mathrm{v})$.

$\mathrm{L}-\left[U-{ }^{14} \mathrm{C}\right]$ Proline from Nuclear-Chicago, specific activity $158 \mathrm{mC} / \mathrm{mmole}$.

\section{RESULTS}

\section{Sodium cyanide}

The results of a typical experiment on the effect of $5 \mathrm{mM} \mathrm{NaCN}$ on the 2-min uptake of L-tryptophan are shown in Table II. The spectrophotometric method for tryptophan was used in this experiment. The results were calculated in terms of 
TABLE II

EFFECT OF CYANIDE ON TRANSPORT AND EXCHANGE OF L-TRYPTOPHAN

The X-cells were first incubated for $30 \mathrm{~min}$ with $20 \mathrm{mM} \mathrm{L}$-methionine; the T-cells had a 30 -min incubation with KRP-solution. The uptake of L-tryptophan was measured for a 2 -min period of incubation.

\begin{tabular}{|c|c|c|c|c|c|c|c|}
\hline \multirow{2}{*}{$\begin{array}{l}\text { Transport }(T) \\
\text { or } \\
\text { exchange }(X)\end{array}$} & \multirow{2}{*}{$\begin{array}{l}\text { Cyanide } \\
(m M)\end{array}$} & \multicolumn{4}{|c|}{ L-Tryptophan found } & \multirow[b]{2}{*}{$\begin{array}{l}\text { Mean } \\
\text { uptake } \\
\left(\frac{\mu \text { moles }}{g d r y \text { wt. }}\right)\end{array}$} & \multirow[b]{2}{*}{$\begin{array}{l}\text { Recovery } \\
(\%)\end{array}$} \\
\hline & & $\begin{array}{l}\text { Total pellet } \\
\text { intracellular } \\
\text { (mmoles) }\end{array}$ & $\begin{array}{l}\text { Extracellular } \\
\text { concn. } \\
\left(\frac{\text { mmoles }}{\text { kg water }}\right)\end{array}$ & $\begin{array}{l}\text { Intracellula } \\
\text { L-tryptopha } \\
\left(\frac{\text { mmoles }}{\text { hg water }}\right)\end{array}$ & $\left(\frac{\mu m o l e s}{g d r y \text { wot. }}\right)$ & & \\
\hline $\mathrm{T}$ & o & $0.00023^{8}$ & I.95 & $3 \cdot 48$ & 7.13 & 7.615 & 98.7 \\
\hline $\mathrm{T}$ & o & 0.000272 & I.94 & 3.99 & 8.10 & & 99.1 \\
\hline $\mathrm{T}$ & 5 & 0.000185 & 2.03 & 2.62 & 5.66 & 5.667 & IOI.2 \\
\hline $\mathrm{T}$ & 5 & $0.000 \mathrm{I} 86$ & 2.02 & $2.6 \mathrm{I}$ & 5.67 & & [ 00.7 \\
\hline $\mathrm{X}$ & o & 0.001479 & I. 37 & 20.07 & 45.22 & 45.976 & I02.0 \\
\hline $\mathrm{X}$ & 0 & 0.001539 & I. 37 & 20.97 & 46.74 & & 103.5 \\
\hline $\mathrm{X}$ & 5 & 0.001457 & I. 42 & 18.45 & 45.03 & $44 \cdot 709$ & 103.9 \\
\hline $\mathrm{X}$ & 5 & 0.001437 & I. 42 & 18.17 & 44.39 & & IO3.0 \\
\hline
\end{tabular}

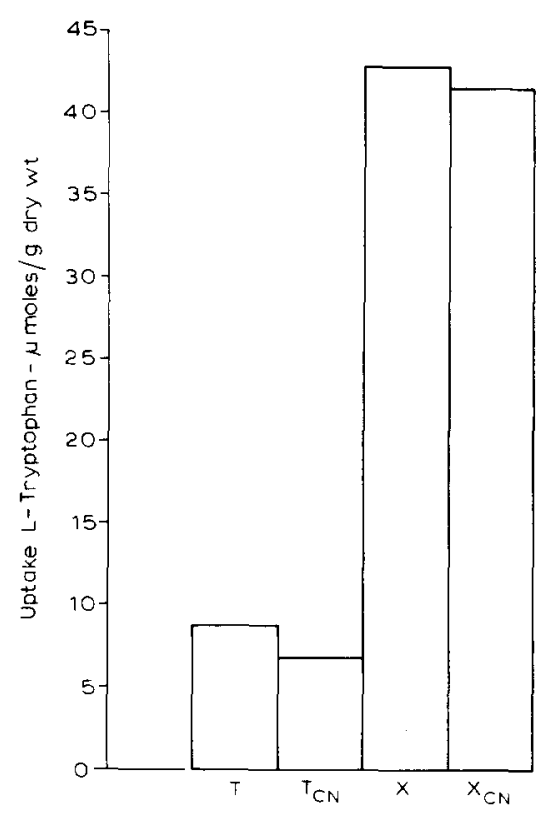

Fig. I. Effect of $5 \mathrm{mM} \mathrm{NaCN}$ on the 2-min uptake of L-tryptophan by transport $\left(T\right.$ and $\left.T_{\mathrm{CN}}\right)$ and by exchange for intracellular methionine $\left(X\right.$ and $\left.X_{\mathrm{CN}}\right)$.

fluxes and in terms of $\mu$ moles/g dry wt. taken up by the cells in the 2 min of incubation. The relative values were approximately the same for either method of calculation. We report our results in terms of $\mu$ moles/g dry wt. because the calculation of fluxes involves the use of the cell counts in our suspensions and these are the least accurate of all our data. Fig. I summarizes the results of nine experiments on the effect of $\mathrm{NaCN}$ on the uptake of L-tryptophan and on the exchange of L-tryptophan for 
L-methionine. The average uptake in the transport tubes $(T)$ was $8.62 \mu$ moles/g dry wt. in the absence of cyanide and 6.70 in the presence of $5 \mathrm{mM}$ cyanide. The average uptake in the exchange tubes $(X)$ was $42.85 \mu$ moles/g dry wt. in the absence of cyanide and $4 \mathrm{I} .46$ in the presence of $5 \mathrm{mM}$ cyanide. The inhibition due to cyanide was $\Delta T_{\mathrm{CN}}=$ $T-T_{\mathrm{CN}}=\mathrm{r} .92 \pm 0.24$ (standard error of mean) for the transport tubes and $\Delta X_{\mathrm{CN}}=X-X_{\mathrm{CN}}=\mathrm{I} .38 \pm 0.52$. The difference between the inhibitions obtained in the transport and exchange situations was $\Delta T_{\mathrm{CN}}-\Delta X_{\mathrm{CN}}=0.54 \pm 0.52$. The recovery of L-tryptophan in these experiments was $100.5 \pm 2.3 \%$. As was to be expected, the recoveries within experiments showed less variation; the standard deviation of recoveries for variation around means within experiments was only I. $48 \%$. Note that although the uptake in the exchange $(X)$ tubes is 5 -fold greater than the transport uptake, the inhibition of exchange uptake is slightly less than the inhibition of transport uptake, however, by the $t$-test, the value of 0.54 for $\Delta T_{\mathrm{CN}}-$ $\Delta X_{\mathrm{CN}}$ is not significantly different from zero at the $5 \%$ level. In these experiments $\Delta T_{\mathrm{CN}}-\Delta X_{\mathrm{CN}}$ was positive in six and negative in three experiments. On a percentage basis, uptake was inhibited $22.3 \%$ in the transport tubes and only $3.2 \%$ in the exchange tubes.

We would expect that uptake in the exchange tubes would consist of exchange plus some transport component. Thus we concluded that the flux of L-tryptophan in exchange for L-methionine is not affected by cyanide but that the transport flux of L-tryptophan is inhibited by cyanide.

\section{2,4-Dinitrophenol}

At the time that the studies on cyanide were run, a similar set of ten experiments were carried out following the same experimental protocol but with use of 2,4-dinitrophenol at a concentration of I $\mathrm{mM}$ in extracellular fluid. The results are given in Table III. In contrast with the results obtained with cyanide, although the inhibition of exchange uptake was less than that of transport uptake (I4.7 vs. 37.I \%), the decrease in exchange uptake in the presence of I $\mathrm{mM} \mathrm{2,4-dinitrophenol} \mathrm{was} \mathrm{greater}$ in amount than the decrease in transport. However, the concentration of 2,4 -dinitrophenol which we used was unusually high and it seemed likely that we were seeing effects of 2,4-dinitrophenol above and beyond those attributable directly to inhibition of cellular metabolism. In work on isolated mitochondria, SIEkEvitz AND POTTER ${ }^{11}$ have shown that almost maximum depression of ATP levels is obtained at $45 \mu \mathrm{M} 2,4$-dinitrophenol and full stimulation of $\mathrm{O}_{2}$ uptake at $\mathrm{I} 5 \mu \mathrm{M} 2,4$-dinitrophenol. Therefore a number of experiments were run, this time with use of $L-\left[{ }^{14} \mathrm{C}\right]$ tryptophan, at a number of different concentrations of 2,4 -dinitrophenol. These results are also given in Table III. The inhibition of transport uptake changed little when the concentration of 2,4-dinitrophenol was dropped to o.I $\mathrm{mM}$ but there was a considerable decrease in the inhibition of uptake in the exchange tubes; at $0.1 \mathrm{mM} \mathrm{2,4-dinitro-}$ phenol the transport uptake was inhibited $26.9 \%$, the uptake in the exchange tubes was inhibited only $6.0 \%$. These results fitted in with our conjecture that the effects seen at I mM 2,4-dinitrophenol were mediated by mechanisms other than direct inhibition of cellular metabolism. The results of the experiment run at Io $\mu \mathrm{M} 2,4-$ dinitrophenol strengthens this argument.

In spite of the above arguments the results with 2,4-dinitrophenol leave room for doubt. For this reason we sought an inhibitor which depletes cellular ATP stores 


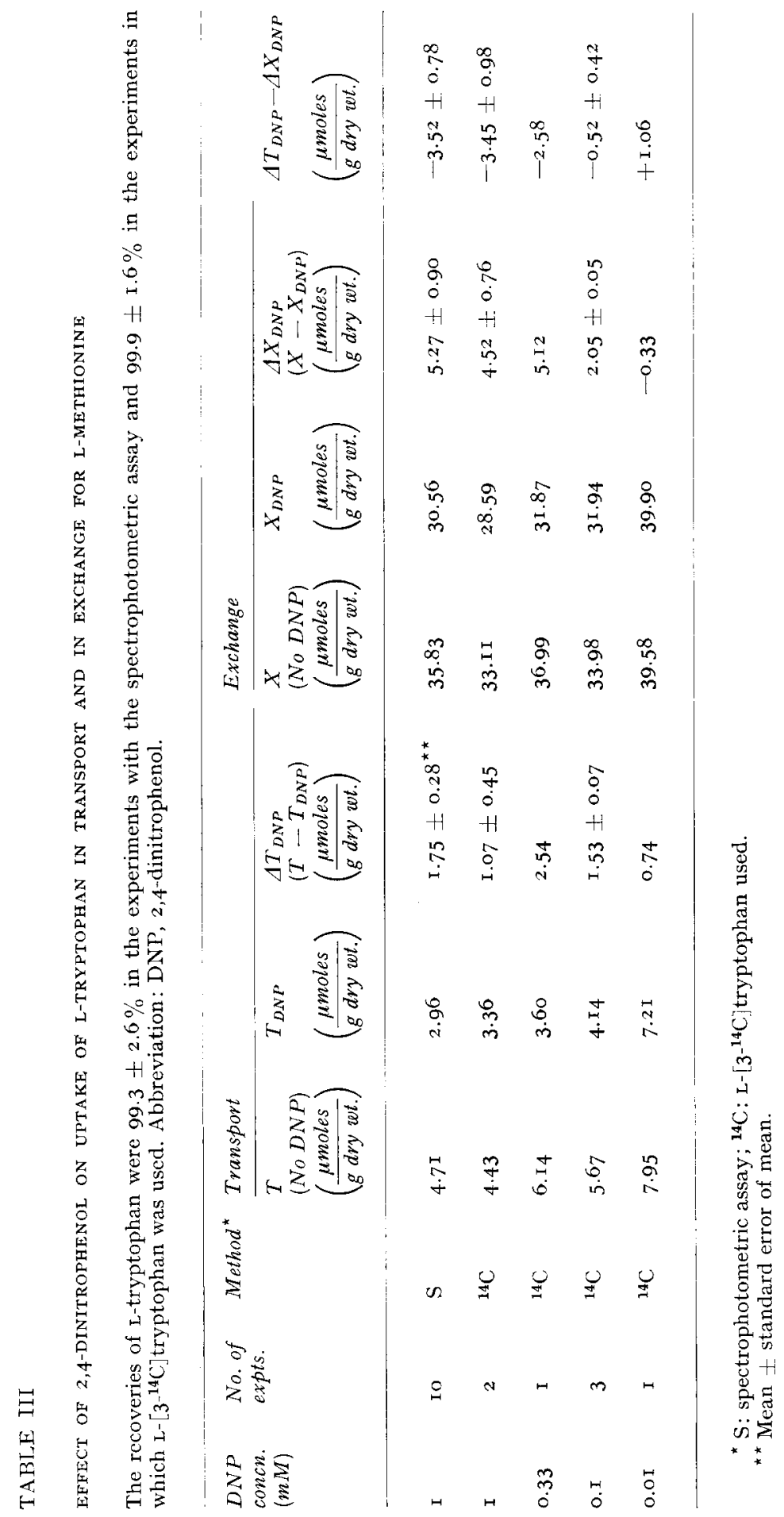

Biochim. Biophys. Acta, Iog (I965) I28-14I 
by acting as a trap for high-energy phosphate and which, except for this reaction, is metabolically inert.

\section{2-Deoxy-D-glucose}

From the evidence which is available, 2-deoxyglucose meets all of the requirements set forth above ${ }^{12-15}$. 2-Deoxyglucose is phosphorylated but not metabolized further ${ }^{\mathbf{1 2}}$. When Ehrlich ascites cells are incubated with $6.8 \mathrm{mM}$ 2-deoxyglucose, the cellular ATP level falls from about $3.4 \mu$ moles $/ \mathrm{ml}$ of cells to about $0.4 \mu \mathrm{mole} / \mathrm{ml}$ of cells within I min and remains at that level for at least $5 \mathrm{~min}$ (ref. I3). With Krebs ascites tumor cells, the ATP level falls, AMP rises and there is an accumulation of IMP and inosine in the cells which have been treated with 2-deoxyglucose. The latter appear as a result of the deamination of the adenine nucleotides ${ }^{\mathbf{1 4}}$.

All of the experiments with 2-deoxyglucose were run at an extracellular concentration of 2-deoxyglucose of ro $\mathrm{mM}$. A preliminary incubation of $\mathrm{I}$ min was used before tipping the Heinicke tubes, this was followed by a 2-min incubation. In most of these experiments, the cell suspensions were split into three parts for the preliminary loading incubation; one was incubated with KRP-solution, the other two were each incubated with a different amino acid. This allowed us to compare the transport uptake of an amino acid with the exchange uptakes for two different amino acids within one experiment. The results are given in Table IV. In almost all cases ( 28 of 35) the inhibition of uptake in the exchange tubes was less than in the transport tubes. This was true whether the uptake in the exchange tubes was less than or greater than the uptake in the transport tubes. The results on tryptophan uptake in the alanine-loaded cells of Expts. 4, 5 and 6 are of particular interest in this regard. The average uptake in transport was 8 .I I6 $\mu$ moles/g dry wt. whereas the uptake in the alanine-loaded cells was only $6.680 \mu$ moles/g dry wt. This indicates that the exchange flux is not independent of the transport flux and fits in well with the concept that exchange and transport fluxes involve the same carrier and thus in effect compete for the carrier. As expected the inhibition in the exchange tubes is much less (average - $0.937 \mu$ mole/g dry wt.) than in the transport tubes (average $-3.040 \mu$ moles/g dry wt.). Apparently alanine has a high affinity for the carrier in comparison to tryptophan as well as in comparison to the "active transport" mechanism. This results in a lower uptake of tryptophan in the exchange situation; however, some transport flux remains which is still inhibitable. The results obtained on L-tryptophan uptake are shown on a relative basis in Fig. 2. For this purpose, the tryptophan uptake in the transport tubes was set equal to 1.0 for all experiments and the other results were expressed relative to this. Again, note that the 2 -deoxyglucose effect is less in the exchange tubes than in the transport tubes, no matter what the relative magnitude of the uptake in the exchange tubes.

The data obtained on glycine differ from those on tryptophan. It appears as if the transport flux is not much smaller (estimated from amount of inhibition obtained with 2-deoxyglucose) in cells loaded with methionine, glycine and proline but is considerably decreased in the cells loaded with alanine or tryptophan. Such data on inhibition of transport and exchange could be used to set up an ordering of affinities for the carrier. The unusually high values of glycine uptake obtained in Expt. I3 are unexplained.

Fig. 3 gives in histogram form the distribution of all values of $\Delta T_{\mathrm{DOG}}-\Delta X_{\mathrm{DOG}}$ 


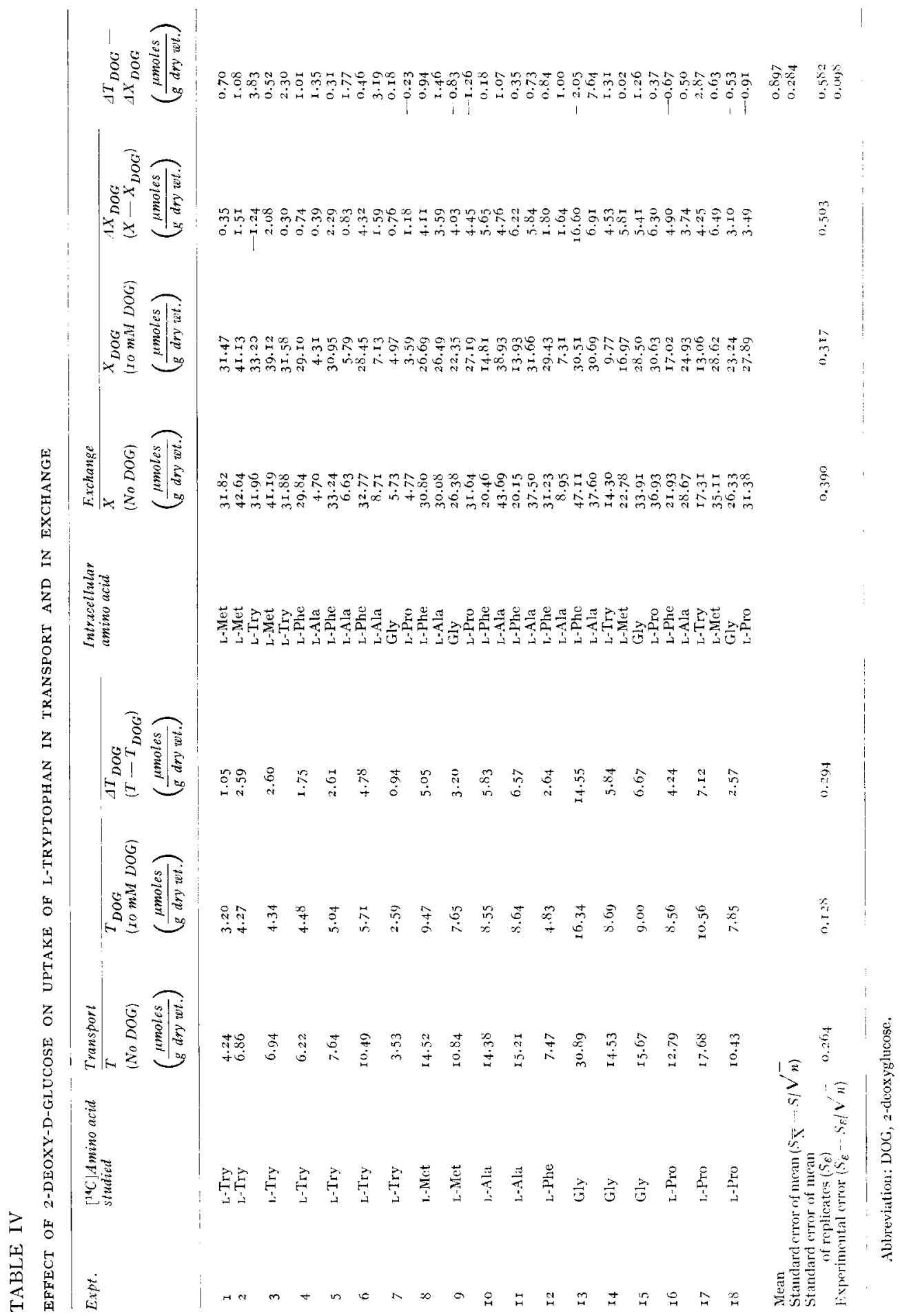

Biochim. Biophys. Acta, Io9 (1965) I28-14 I 
(subscript DOG, denotes 2-deoxyglucose). We may consider each determination of $y=\Delta T_{\mathrm{DOG}}-\Delta X_{\mathrm{DOG}}$ to contain two major components of variation. We write $y_{i}=\mu+x_{i}+\varepsilon_{i}$, where $i$ stands for the particular experiment. Then $\mu$ is the overall mean value for the different samples of ascites, $x_{i}$ is a random variable of mean zero
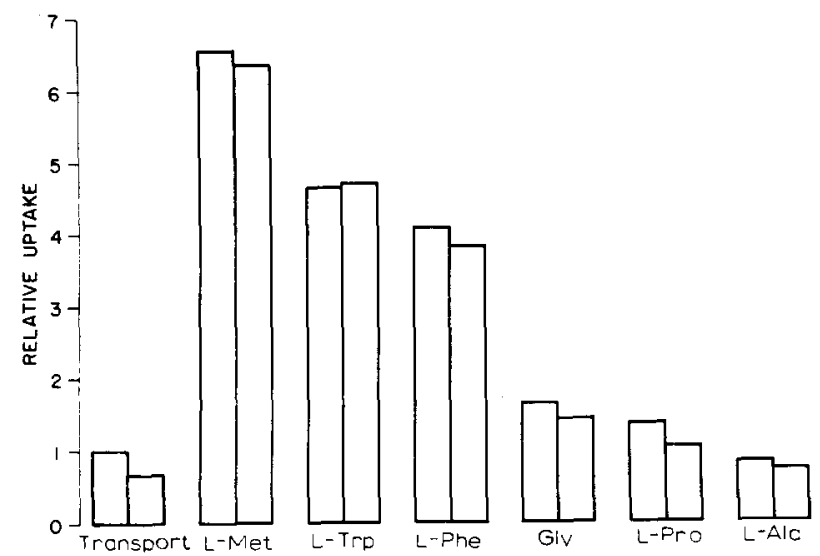

Fig. 2. The effect of 2-deoxyglucose on the relative uptake of $L$-tryptophan by cells which had not been preloaded (transport) and by cells preloaded with L-methionine, L-tryptophan, L-phenylalanine, glycine, L-proline and L-alanine. For each of the pair of columns, the left one gives the 2 -min relative uptake in the absence of 2 -deoxyglucose, the right one gives the relative uptake in the presence of Io $\mathrm{mM}$ 2-deoxyglucose.

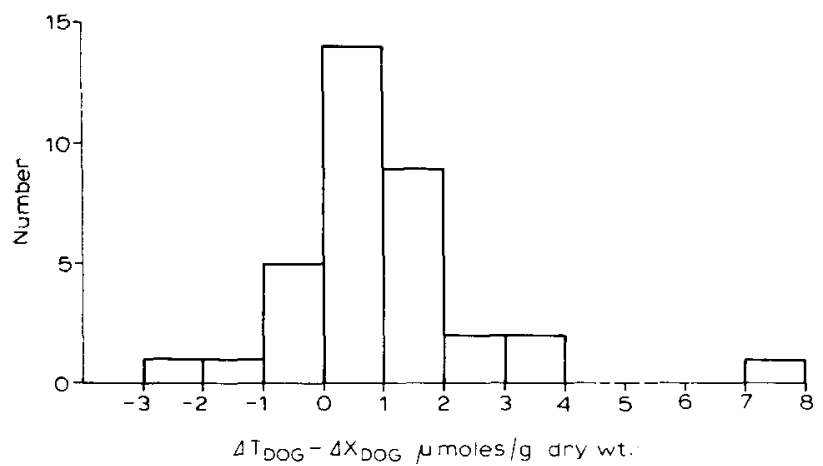

Fig. 3. The distribution of the difference between the effects of 2 -deoxyglucose (DOG) on uptake in transport tubes $(T)$ and exchange tubes $(X)$.

which gives the fluctuation due to variation in ascites and in day of experiment, $\varepsilon_{i}$ is a random variable of mean zero which gives the over-all error of technique within experiments. The variance of the $y_{i}$ is given by

$$
S^{2}=\frac{\mathrm{I}}{n-\mathrm{I}}\left[\sum_{i}\left(x_{i}-\bar{x}\right)^{2}+2 \underset{i}{\Sigma}\left(x_{i}-\bar{x}\right)\left(\varepsilon_{i}-\bar{\varepsilon}\right)+\sum_{i}\left(\varepsilon_{i}-\bar{\varepsilon}\right)^{2}\right]
$$

where $\vec{\varepsilon}$ is the sample mean of the $\varepsilon_{i}$. This is an estimate of the expected value of $S^{2}$ which is

$$
E\left(S^{2}\right)=\sigma^{2}+\sigma_{\varepsilon}^{2}
$$


where $\sigma^{2}$ is the variance in the population of $x_{i}$ and $\sigma_{\varepsilon}{ }^{2}$ is the variance of the population of errors. Thus the variance of the mean of the $\Delta T_{\mathrm{CN}}-\Delta X_{\mathrm{CN}}$ is an estimate of $\sigma^{2} / n+\sigma_{\varepsilon}{ }^{2} / n$. The value of $S_{\varepsilon}{ }^{2}$, the sample estimate of $\sigma_{\varepsilon}{ }^{2}$ is obtained from the replicates in our experiments. The contribution to the standard error of the mean of $\Delta T_{\text {DoG }}$ $\Delta X_{\mathbf{D O G}}$ due to the error term is therefore, $S_{\bar{\varepsilon}}=\mathrm{I} / \sqrt{n} S_{\varepsilon}=0.098$. The mean value of 0.897 with a standard error of the mean of 0.284 is significantly different from zero at the $0.00 \mathrm{r} \%$ level in the Student $t$-test. If the distribution-free sign test is used, the results also differ significantly from zero. On the hypothesis that the median value of $\Delta T_{\mathrm{DOG}}-\Delta X_{\mathrm{DOG}}$ is zero (i.e. that the transport flux is present independent of the exchange flux in the preloaded cells), the probability, $P\left[\Delta T_{\mathrm{DOG}}-\Delta X_{\mathrm{DOG}}>0\right]$ $=0.5$. Then the probability that 28 or more samples out of 35 would be positive is only 0.0025 . The results of the analysis are the same if we examine the distributions of $\left(\Delta T_{\mathrm{DOG}}-\Delta X_{\mathrm{DOG}}\right) / \Delta T_{\mathrm{DOG}}$ and of $\left(\Delta T_{\mathrm{DOG}}-\Delta X_{\mathrm{DOG}}\right) / T$. We consider the results to be significant statistically and biologically and interpret them to mean that the transport flux is inhibited by inhibitors of cellular metabolism but that the exchange flux is not inhibited and further that the transport flux is decreased in amount when an exchange flux is also present. The latter is interpreted to mean that the two fluxes utilize the same carrier and in effect compete for it. The seven negative values obtained for $\Delta T_{\mathrm{DOG}}-\Delta X_{\mathrm{DOG}}$ are interpreted as part of the over-all distribution of error (Fig. 3) resulting from the experimental error incurred as a result of handling cells, preparing extracts and carrying out the many measurements involved in these experiments.

\section{DISCUSSION}

From the results presented here we conclude that, for the monoamino-monocarboxylic acids in Ehrlich ascites cells, transport fluxes but not exchange fluxes are inhibited by depression of energy metabolism. Furthermore we conclude that the exchange and transport mechanisms compete for the same carrier. In the light of the currently favored hypothesis that the formation of a complex with a membrane component, a carrier, is the mechanism by which amino acids cross the cell membrane, what are the implications of these findings for the nature of the linkage between carrier and cellular metabolism.

As indicated in Fig. 4, active transport can be considered to consist of four main processes. These are: (I) Movement of carrier across the membrane. (2) Movement of carrier-amino acid complex across the membrane. (3) Formation of carrier-

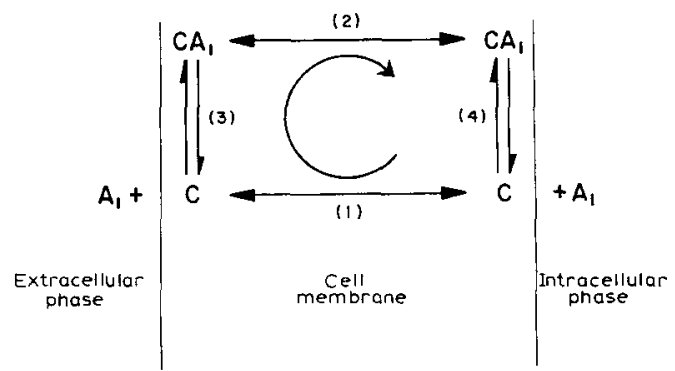

Fig. 4. Schematic diagram of basic processes involved in carrier-mediated active transport of amino acids. 
amino acid complex at the outer surface of the membrane. (4) Dissociation of carrieramino acid complex at the inner surface of the cell membrane. In Fig. 4 the circular arrow indicates the direction in which the cycle must work in order to concentrate amino acids in the cell. A linkage between cellular energy metabolism and any one of the above four processes could run the cycle.
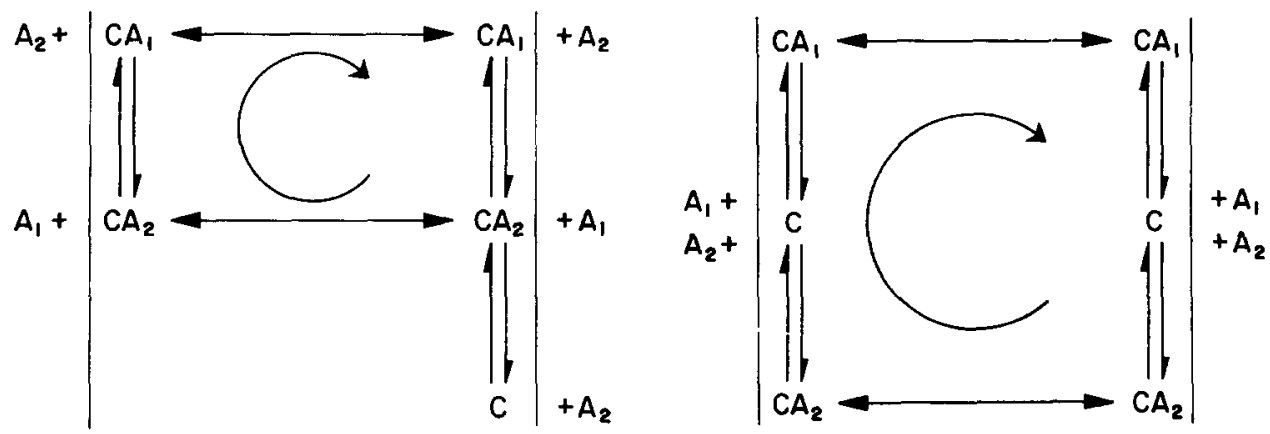

Fig. 5. Diagram of mechanism of displacement (D) type of exchange diffusion.

Fig. 6. Diagram of mechanism of replacement $(R)$ type of exchange diffusion.

Exchange diffusion (counter flow) could conceivably occur by either or both of two mechanisms. These are given in Figs. 5 and 6. We call these displacement (D) type and replacement $(R)$ type of exchange diffusion respectively. Assume we start with amino acid $A_{2}$ intracellularly and $A_{1}$ extracellularly. In the D-type of exchange diffusion (Fig. 5), some $\mathrm{CA}_{2}$ must first be formed by reversal of Process 4 ; subsequent to this, the cycle can run, in the direction indicated by the circular arrow, by the occurrence of displacement or exchange reactions at each surface, reactions which do not involve the formation of free carrier as an intermediate. In the R-type of exchange diffusion, the carrier-amino acid complex dissociates to give free carrier at each surface before the carrier takes on the other amino acid. One of $\mathrm{us}^{16}$ has shown that if the carrier-amino acid complex is assumed to be a $I$ : I complex, then displacement reactions (D-type) must be assumed to occur if we are to explain the experimental finding that some amino acids appear to stimulate uptake of others in experiments on competition between amino acids ${ }^{9,17}$. This, of course, does not rule out the possibility that the R-type of exchange also occurs; it does show that a substantial portion of the exchange flux must be of the D-type.

Let us consider then what the effects of inhibition of cellular metabolism would be for the different types of possible linkages between the carrier system and energy metabolism.

(I) If Process I is linked to cellular metabolism, inhibitors should inhibit transport fluxes but have no effect on exchange fluxes whether of $\mathrm{R}$ - or $\mathrm{D}$-type.

(2) If Process 2 is linked to cellular metabolism, inhibition of cellular metabolism should give inhibition of transport fluxes and of both $\mathrm{R}$ - and D-type exchange fluxes.

(3) If the linkage is through Process 3, we would expect inhibitors to give inhibition of transport flux, inhibition of R-type exchange fluxes and some (perhaps small) inhibition of D-type exchange fluxes. In the D-type of exchange flux, the displacement reaction must compete with the dissociation of carrier-amino acid complex at the outer surface of the cell membrane. Inhibition of formation of complex by 
Process 3 would in effect increase dissociation of $\mathrm{CA}_{1}$ and $\mathrm{CA}_{2}$ at the outer surface of the cell membrane to give some inhibition of the D-type of exchange flux.

(4) Finally, if the linkage to cellular metabolism is through Process 4, inhibitors should inhibit transport fluxes and the R-type of exchange fluxes but have no effect or a stimulatory effect on the D-type of exchange fluxes. Inhibition of dissociation of $\mathrm{CA}_{1}$ and $\mathrm{CA}_{2}$ at the inner surface of the cell membrane should actually favor the D-type of exchange cycle (Fig. 5); thus we may even expect to obtain some stimulation of exchange flux.

From the data presented in this paper we can eliminate Process 2 as the site of linkage between carrier system and cellular metabolism. Process 3 cannot be eliminated categorically but in terms of the above discussion and our results, it seems to be a less likely process for linkage to cellular metabolism. However, both Processes I and 4 remain as likely sites for linkage to cellular metabolism. On the basis of the qualitative arguments presented here and the data we have obtained there is no way of distinguishing between these two possibilities.

So far we have considered our results only in terms of a one-carrier hypothesis. OXENDER AND ChRIstensen ${ }^{18}$ have proposed that there are two transport systems for the neutral amino acids in Ehrlich ascites cells which they call the L (leucine) and the A (alanine) systems. Entry of leucine, isoleucine, valine and phenylalanine is mediated primarily by the L-system, entry of alanine, glycine, proline, serine, threonine, asparagine and glutamine is mediated primarily by the A-system but methionine has strong affinity for both systems. Furthermore, the authors assume that all amino acids have some affinity for both systems. They further argue that the L-system plays a predominant role in exchange diffusion and in support of this they report that glycine and alanine (A-system) give little stimulation of exchange diffusion. However, our results contradict this. For some amino acids we have obtained considerable exchange uptake in cells loaded with glycine, L-proline and L-alanine (Table IV).

It is true that in some respects glycine, $\mathrm{L}$-proline and $\mathrm{L}$-alanine are more alike and that tryptophan and phenylalanine also seem to be more alike but we see no compelling reason in our data or in those presented by OXENDER AND CHRISTENSEN to assume the existence of two transport systems which have overlapping specificities. As one of their arguments, these authors propose that the competitive stimulation of uptake of L-tryptophan by L-methionine ${ }^{9}$ might be explained as follows: L-methionine enters the cells by $\mathrm{A}$ - and L-mechanisms and then by exchange diffusion, mediated by the L-system, stimulates uptake of $\mathrm{L}$-tryptophan. However, as GURoFF et al. ${ }^{17}$ have shown, L-phenylalanine also stimulates uptake of L-tryptophan in a competitive situation. But according to OXENDER AND CHRISTENSEN both phenylalanine and tryptophan enter cells primarily by the L-system. Thus GURoFF's results effectively destroy what we considered the only good reason for considering the two-carrier hypothesis. We $\mathrm{e}^{16}$ agree with GUROFF et al. ${ }^{17}$ that the phenomenon of competitive stimulation is probably best explained by the occurrence of the displacement type of reactions.

Until more definitive evidence is found, we see no reason to postulate the existence of two carriers. One can with equal justification and with some saving of hypotheses relate the differences between the above mentioned two groups of amino acids to differences in affinities for one carrier and to differences in the ease with which one amino acid displaces another from the carrier-amino acid complex. 


\section{ACKNOWLEDGEMENTS}

This investigation was supported in part by U.S. Public Health Service Research Grant Nos. CA-06734-02 and CA-06734-03 from the National Cancer Institute.

The authors thank Miss M. FAUlk, Mrs. J. O'Brien and Mr. J. Terris for their able technical assistance.

\section{REFERENCES}

I H. H. Ussing, Nature, I6o (I947) 262.

2 E. Heinz and P. M. Walsch, J. Biol. Chem., 233 (1958) I 488.

3 R. M. Johnstone and P. G. Scholefeld, Cancer Res., i9 (I959) I I 4 o.

4 J. A. Jacquez, Am. J. Physiol., 200 (I96I) Io63.

5 T. Rosenberg and W. Wilbrandt, $J$. Gen. Physiol., 4 I (I957) 289.

6 W. Wilbrandt and T. Rosenberg, Pharmacol. Rev., I3 (I96I) Io9.

7 J. A. J acouez, Proc. Natl. Acad. Sci. U.S., 47 (I96I) I53.

8 J. A. JACQUez, Federation Proc., I9 (I960) I27.

9 J. A. JaCQUEz, Biochim. Biophys. Acta, 7 I (I963) I 5.

Io J. A. JACQUez, Cancer Res., I7 (I957) 890.

i I P. Siekevitz and V. R. Potter, $J$. Biol. Chem., 20 I (I953) I.

I2 K. H. Ibsen, E. L. Coe And R. W. McKeE, Biochim. Biophys. Acta, 30 (I958) $3^{84}$

I3 K. Ibsen, E. L. Coe and R. W. McKee, Cancer Res., 22 (1962) I82.

I 4 R. B. МсСомB AND W. D. Yushok, Cancer Res., 24 (1964) Ig8.

I5 K. Letnansky, Biochim. Biophys. Acta, 87 (I964) I.

I6 J. A. JacQuez, Biochim. Biophys. Acta, 79 (I964) 3 I8.

I 7 G. Guroff, G. R. Fanning and M. A. Chirigos, J. Cellular Comp. Physiol., 63 (I964) 328.

i 8 D. L. Oxender and H. N. Christensen, J. Biol. Chem., 238 (I963) 3686. 